\title{
A CONSTRUÇÃO DA MASCULINIDADE E A MISOGINIA NO CONTO COMEÇOS DE UMA FORTUNA, DE CLARICE LISPECTOR (1960)
}

\author{
THE CONSTRUCTION OF MALE AND MISOGINY IN THE CONTO THE BEGINNING OF A \\ FORTUNE, BY CLARICE LISPECTOR (1960)
}

\author{
Kaoana Sopelsa ${ }^{1}$ \\ Fausto Alencar Irschlinger ${ }^{2}$
}

${ }^{1}$ Mestranda em Educação pela Universidade do Oeste do Paraná; especialização em História, Arqueologia e Patrimônio Cultural - Universidade Paranaense.

2Professor da especialização em História, Arqueologia e Patrimônio Cultural da Universidade Paranaense.

SOPELSA, K.; IRSCHLINGER, F. A. A construção da masculinidade e a misoginia no conto Começos de uma Fortuna, de Clarice Lispector (1960). Akrópolis. Umuarama, v. 25, n. 1, p. 35-46, jan./jun. 2017.

\section{DOI: 10.25110/akropolis.v25i1.6672}

Resumo: Brasil, século XX. Clarice Lispector, literata e jornalista, elaborou contos, colunas de jornais e livros. O conto da autora aqui analisado, intitulado Começos de uma fortuna, é passível de análise por demonstrar as relações de gênero, perpassando pelas relações de poder e de hierarquia dos papéis sociais binários. Com o intento de aclarar sobre a construção da masculinidade, para então constatar a misoginia por meio da representação do personagem principal Artur, empregamos a Análise do Discurso Francesa com Michel Foucault, almejando explanar as interdições do discurso de gênero, de família nuclear, no intuito de compreender o padrão definido por este discurso, para então atender a hipótese levantada, ou seja, de que forma a construção da masculinidade se exibe no discurso do protagonista e das representações que o rodeiam, e se, a partir do discurso adotado por Clarice Lispector em suas linhas, o olhar do personagem principal conduzido às mulheres com as quais se inter-relaciona e tem a possibilidade ser identificado como misógino. Na análise, nos parece que Artur anseia pela dominação masculina, adotando como representação estereotipada a figura paterna de autoridade e proprietário dos demais integrantes da família, assim como a representação de um homem bem-sucedido lhe é desejada. Seu desprezo pela representação feminina é de tal forma aguçado que ele maldiz esses sujeitos femininos, demonstrando Artur afeiçoa-se às representações de discursos como a misoginia e a dominação masculina, num conjunto de percepções e pensamentos que nos levam a considerar tais definições. Por fim, a literatura se apresenta enquanto fonte de análise histórica do que se silenciava por parte da anterior história oficial.

PalaVRas-chaVe: Clarice Lispector; Masculinidade; Misoginia; Representação.

ABSTRACT: Brazil, twentieth century. Clarice Lispector, literata and journalist, elaborated short stories, columns of newspapers and books. The tale of the author analyzed here, entitled "Beginnings of a Fortune", can be analyzed by demonstrating gender relations through the relations of power and hierarchy of binary social roles. In an attempt to clarify the construction of masculinity, and then to verify the misogyny through the representation of the main character Arthur, we use the French Discourse Analysis with Michel Foucault, aiming to explain the interdictions of the gender discourse, nuclear family, in order to understand the pattern defined by this discourse, to answer the hypothesis raised, that is, how the construction of masculinity is exhibited in the discourse of the 
protagonist and of the representations that surround him, and if, from the discourse adopted by Clarice Lispector in its lines, the look of the main character led to the women with whom it interrelates has the possibility to be identified as misogynistic. In the analysis, it seems to us that Arthur longs for male domination, adopting as stereotypical representation the paternal figure of authority and owner of the other members of the family, just as the representation of a successful man is desired. His contempt for female representation is so sharp that he curses these female subjects, demonstrating that Arthur is fond of representations of discourses such as misogyny and male domination in a set of perceptions and thoughts that lead us to consider such definitions. Finally, literature presents itself as a source of historical analysis of what was silenced by the previous official history.

KeYwORDs: Clarice Lispector; Masculinity; Misogyny; Representation.

\section{INTRODUÇÃO}

No Brasil do século XX, Clarice Lispector operou como literata e jornalista, elaborando contos, colunas de jornais e livros notáveis. A autora foi considerada uma mulher singular para sua época, já que mesmo cumprindo os papéis sociais femininos de mãe e esposa, não abandonou sua atuação como escritora, sobressaindo-se na literatura nacional.

Após realizar a leitura do conto Começos de uma Fortuna, da autora Clarice Lispector, alguns questionamentos se fizeram presentes, como a possível negação da masculinidade do protagonista Artur. Todavia, ao reler o conto e alguns livros sobre a construção da masculinidade, percebemos que não se tratava bem disso, mas que a hipótese deveria ser elaborada sobre a construção da masculinidade de Artur, assim como seus modelos de sujeito, e como esta construção, possivelmente, perpassa para a misoginia demonstrada pelo protagonista, cujo perfil é de um jovem estudante de classe média de meados da década de 1950 (levando em consideração a escrita do conto, grande parte efetuada no exterior, publicado pela primeira vez em 1960, no Brasil).

Para analisar a construção da masculinidade de Artur, os estereótipos admirados por ele, assim como a possível misoginia em suas falas, faz-se necessário analisar as relações de gênero contidas no conto, relacionando com os discursos sociais do período em que o conto foi escrito.

A literatura serve como demonstração, expressão e veiculação dos discursos sociais que constituem parte da análise histórica. No conto Começos de uma fortuna, Clarice Lispector pode demonstrar a tomada de posição acerca dos papéis sociais de gênero. Intencionando elucidar sobre a construção da masculinidade, para então encontrar a misoginia por meio da representação do protagonista Artur, fazemos uso da Análise do Discurso Francesa com Michel Foucault, visando a elucidar as interdições do discurso binário, de família nuclear, na tentativa de compreender o padrão definido por este discurso, para então responder a hipótese levantada, ou seja, de que forma a construção da masculinidade se apresenta no discurso do protagonista e seus pares, e se, a partir do discurso adotado pela autora, o olhar do protagonista direcionado às mulheres com as quais se relaciona diretamente pode ser classificado como misógino.

As obras de Clarice Lispector costumam ser analisadas por pesquisadores, principalmente, da área literária e linguística, enfatizando a leitura, a escrita da autora. Lembramos que aqui nosso foco é analisar discursivamente o conto, compreendendo as possíveis interdições sociais que esse discurso apresenta.

\section{OS LUGARES DE ARTUR}

As famílias do século $X X$ conheceram uma conjuntura de modernidade, ou seja, de modelos idealizados, nos quais a instituição familiar e o casamento disciplinariam e controlariam as pessoas, além de "assegurar a permanente sujeição das mulheres aos homens e de controlar sua autonomia e independência financeira e política" (MAIA, 2011). Os reflexos sociais desse discurso podem ser observados no conto que aqui analisaremos.

Entre os anos de 1920 e 1950, a juventude burguesa pôde escapar da vigia dos pais, que não mais interferiam diretamente em suas escolhas de amor conjugal ${ }^{3}$, e compartilhar com seus pares nos momentos de lazer. Neste ínterim, a juventude pode idealizar e apreciar/depreciar os papéis de gênero dos adultos, enquanto

\footnotetext{
${ }^{3}$ De acordo com Jurandir Freire Costa (2004), o amor foi o argumento pelo direito de escolha do cônjuge, antes indicado pelo grupo familiar. Entretanto, com ele, novas obrigações surgiram, como a responsabilidade pelo funcionamento, o compromisso familiar, onde a dissolução não deveria ocorrer, já que os cônjuges puderam se unir por vontade própria, então a união precisava dar certo. As pressões sociais aumentaram, nesse sentido.
} 
aproveitam seu estado intermediário.

O prolongamento da adolescência e a autonomia que ela adquiriu progressivamente generalizaram a participação dos jovens em grupos informais de amigos da mesma idade. Na vasta classe média, que forma atualmente o essencial das sociedades ocidentais, esses grupos desempenham um papel de primeira ordem na lenta transição entre o universo familiar da infância e a autonomia adulta. Eles permitem, principalmente aos adolescentes, o confronto com campos mais vastos de experiência, entre pares ou com colegas do sexo oposto, que acompanham a construção e a afirmação de sua identidade de gênero (BAUBÉROT, et al., 2013, p. 217 e 218).

Apesar da citação se referir à atualidade, podemos visualizar a raiz dessa formação, chamada de adolescência, no conto estudado. Clarice apresenta-nos três cenários: primeiramente o familiar, de maior convívio com a figura materna, já que o ambiente feminino adequado dentro dos papéis sociais do período é o privado, já que:

A presença feminina no cenário urbano incomodava de várias maneiras; seja como trabalhora, seja como prostituta; fumando ou usando roupas mais curtas. Desconhecida, a sexualidade feminina se tornava um grande medo e uma atração (RAGO, p. 1991, p. 121).

Ideia essa justificada pelo seguinte discurso:

De modo geral, herdeiros das luzes, médicos e juristas reforçavam os argumentos de que as mulheres em geral possuíam um físico débil e um temperamento frágil, razões pelas quais deveriam estar mais sujeitas à vigilância do que os homens. Sua entrada na esfera pública só poderia ser muito conturbada (Idem, p. 144).

Ou seja, que as mulheres se recolhessem ao confinamento, já que fracas e frágeis, para não despertarem a atração de olhares, sendo consideradas propriedade de um homem, um marido que as protegeria de si mesmas e dos outros. "O marido é considerado o "chefe da casa" e deve sustentá-la economicamente, enquanto a esposa deve se ocupar das tarefas domésticas e dos cuidados com os familiares" (PINSKY, 2014, p. 209). E continua,

Apesar dos vários arranjos familiares encontrados na população brasileira, o modelo dominante é o nuclear - aquele da família composta por casal com filhos vivendo sob o mesmo teto. Na classe média dessa época, as famílias são, de fato, tipicamente nucleares e o número de filhos em cada uma é reduzido em comparação com os padrões do passado. A preocupação com o nível educacional dos filhos, a procriação limitada e a privacidade são valores importantes nesse grupo social (Idem, p. 211).

Como sugerido, essa família idealizada era parte de um discurso do período, que desejava reformular a realidade social, impondo estereótipos e papéis de gênero, nos quais as mulheres não eram consideradas iguais aos homens, discurso inclusive visualizado nos Códigos Civis brasileiros pós-Proclamação da República, que traziam a mulher como ser inferior e subordinado. Nesse sentido, o homem tinha obrigação de ser o provedor da família, e em resposta a isso, as mulheres tinham o direito à proteção desse homem, entregando-lhe sua autonomia, devendo-lhe obediência, em que a protegida é considerada de menor valor, e depende de um protetor (MAIA, 2011).

Em seguida, o conto aborda a escola mista, mesmo que rara ainda nesta década:

A escola também tem o papel determinante na formação e distinção dos gêneros. Nesse período, existiam muitas escolas privadas, normalmente dirigidas por padres ou freiras, que mantinham a divisão sexual no ensino. Depois do primário, os garotos optavam pelo científico (com ênfase nas ciências ditas "duras"), clássico (cujo eixo estava centrado nas áreas de ciências humanas e sociais) ou ainda algum outro curso técnico, como o de contabilidade. Já a grande maioria das garotas optava pelo curso normal (SANT'ANNA, et al., 2013, p. 303).

Os papéis de gênero também podem ser visualizados pela educação, que direcionava aos gêneros o que deveriam saber, de acordo com suas funções sociais. Para Maia (2011), as garotas aprendiam sobre administração das despesas domésticas como forma de compensar a inexistência de uma carreira profissional, a 
chamada Economia Doméstica, no curso superior, que enfatizava a solução de problemas familiares, o uso de aparelhos eletrodomésticos, o estudo da alimentação, do vestuário, por exemplo. Os currículos escolares, de acordo com a autora, direcionavam o ensino para formação de mulheres que gerenciassem a vida doméstica e a maternidade de forma inteligente, sem obrigação alguma sobre o trabalho produtivo.

E, por fim, o conto nos leva ao cinema, uma novidade de lazer raramente aproveitada de forma mista e desregrada, como aparece no conto:

Na construção da identidade do jovem, a produção cultural passa ter grande influência. Ícones da cultura de massa, heróis de cinema, atores, cantores passam a representar os anseios e modismos de diferentes gerações, marcando suas singularidades (Idem, p. 305).

Entretanto, este viés é inserido porque nele se descreve o cotidiano de Artur, aparente filho único de sexo masculino ${ }^{4}$, ou seja, a vigia dos pais em relação aos meninos é muito menor, assim como a possibilidade de vivenciar momentos como este.

Mesmo que o conto tenha sido escrito em português e a moeda referida ("cruzeirinhos") ser de uso do Brasil, não há necessidade de aprofundamento acerca da história brasileira do período, porque Clarice não se encontrava no Brasil durante a década de 1950 quase integralmente ${ }^{5}$, mas mantinha contato com amigos e familiares que permaneceram no país.

\footnotetext{
${ }^{4}$ Artur como filho único nos sugere a transição afirmada por Peter N. Stearn (2010) de que, após a explosão de nascimentos, conhecida como "baby boom", onde as famílias costumavam ter entre três ou quatro filhos, a taxa de natalidade cai para um ou dois filhos, graças a ideia de vincular o sexo somente à procriação, assim como a maior difusão de meios para controlar a natalidade. ${ }^{5}$ De acordo com Benjamin Moser (2011), em 1943 a autora casou com Maury Gurgel. No fim do ano, o primeiro romance da autora foi publicado: Perto do Coração Selvagem conseguindo, logo em seguida, o Prêmio Graça Aranha de melhor obra escrita em 1943. Pouco se passou e o casal deixou o Rio de Janeiro por cerca de vinte anos - com curtos momentos de retorno. O casal vinculado ao exercício da diplomacia conheceu a realidade de diferentes países, além de alguns de passagem, como o Egito. Em 1944 moraram na Itália e viajaram pela Europa. Em 1946 retornaram ao Brasil por cerca de três meses. Voltaram a Europa, porém residindo na Suíça. Em 1949, a família retorna ao Rio de Janeiro. No ano seguinte, mudam-se para a Inglaterra. Em março de 1951, voltam ao Rio. Em setembro de 1952, mudam-se para os Estados Unidos da América. Em 1954 Clarice permanece no Rio com os filhos por cerca de três meses, retornado aos Estados Unidos. Em 1959 a autora volta ao Brasil com os filhos, divorciada, para ficar.
}

\section{METODOLOGIA}

Trabalhar com literatura dentro da história exige que ocorra contribuição temporal, social, respondendo questionamentos sobre o papel social de gênero no período histórico em que a fonte está inserida. Na perspectiva da interdição discursiva deve-se levar em consideração que a definição do modo de ser homem está fundamentalmente ligada aos discursos produzidos.

O discurso, para Foucault (2011), "está na ordem das leis", tem seu poder e advém dos sujeitos. Dessa forma, as palavras reproduzem uma realidade material, sendo que a realidade representada, assim como o discurso, é "controlada, selecionada, organizada e redistribuída por certo número de procedimentos" que revelam desejo e poder, ou seja,

Por mais que o discurso seja aparentemente bem pouca coisa, as interdições que o atingem relevam logo, rapidamente, sua ligação com o desejo e com o poder. Nisto não há nada de espantoso, visto que o discurso como a psicanálise nos mostrou - não é simplesmente aquilo que manifesta (ou oculta) o desejo; é, também, aquilo que é o objeto de desejo; e visto que - isto a história não cessa de nos ensinar - o discurso não é simplesmente aquilo que traduz as lutas ou os sistemas de dominação, mas aquilo por que, pelo que se luta, o poder do qual nos queremos apoderar (Idem, p. 10).

Desta forma, podemos afirmar que o desejo de exercer a dominação masculina, de representar e se apropriar de um estereótipo masculino durante a construção da masculinidade, assim como de seu papel social de gênero, abre precedente para o discurso misógino, de desprezo ao papel social feminino e de homogeneização da representação desse gênero.

As representações podem ser consideradas geradoras de comportamentos e práticas sociais, demonstrando visões de mundo e explicando experiências e cotidianos. Ao analisar os discursos e as representações por ele trazidas é possível significar e interpretar o mundo social, suas práticas e construções. Para Chartier, é possível que, a partir da representação, a submissão e o respeito sejam colocados como reais, mesmo que tenham sido fabricados, permitindo a dominação. 
A relação de representação é, desse modo, perturbada pela fraqueza da imaginação, que faz com que se tome o engodo pela verdade, que considera os signos visíveis como índices seguros de uma realidade que não o é. Assim desviada, a representação transforma-se em máquina de fabricar respeito e submissão, num instrumento que produz uma exigência interiorizada, necessária exatamente onde faltar o possível recurso à força bruta (CHARTIER, s.d., p. 185 e 186).

A dominação masculina pode ser exercida, de acordo com Bourdieu (2002), por maneiras de pensar, de agir, que se tornam naturalizadas a partir de um sistema de diferenças, que no caso das relações de gênero se determinam e se legitimam pelas diferenças biológicas. $O$ mundo social é apresentado com divisões arbitrárias, legitimadas de tal forma que nem precisam mais de justificação. Para o autor,

\begin{abstract}
A força da ordem masculina se evidencia no fato de que ela dispensa justificação: a visão androcêntrica impõe-se como neutra e não tem necessidade de se enunciar em discursos que visem a legitimá-la. A ordem social funciona como uma imensa máquina simbólica que tende a ratificar a dominação masculina sobre a qual se alicerça: é a divisão social do trabalho, distribuição bastante estrita das atividades atribuídas a cada um dos sexos, a seu local, seu momento, seus instrumentos; é a estrutura do espaço, opondo o lugar de assembleia ou de mercado, reservados aos homens, e a casa, reservada às mulheres (BOURDIEU, 2002, s.p.).
\end{abstract}

Ainda que a dominação masculina coloque como autoridade a representação masculina, alguns deveres em relação ao feminino podem ser revertidos em ressentimento, porque visto enquanto sexo inferior e desprezado. A misoginia, o ódio ou a aversão pelas representações do feminino, é uma construção subjetiva que pode nascer "no seio da sociedade e de suas representações" (Dicionário crítico de gênero $p$. 461). De acordo com a bibliografia citada,

Já o misógino, numa perspectiva essencialista e universalista, experimenta o ódio ou a aversão a todas as mulheres atribuindo-as identidade unificada. A misoginia é uma aversão ao gênero feminino, entendido como universal e abstrato, pois se estende às muIheres como uma identidade única e a mercê de seus contextos históricos e culturais.

(...) A produção de representações que atribuem ao feminino uma série de características malignas. Nesses discursos as mulheres aparecem como ardilosas, frívolas, avarentas, incapazes de produzir conceitos, moralmente fracas e indisciplinadas (Idem, p. 462).

Assim, se o homem, apesar de dominar o feminino ainda demonstra desprezo por seu papel de gênero, é provável que a misoginia esteja presente. Ao acreditarmos que a realidade é arquitetada discursivamente, e essa realidade expõe códigos, marcas, sentidos, forja representações e as empodera, através da Análise do Discurso foucaultiana, os discursos do conto serão analisados e comparados com os estereótipos sociais de dominação masculina, encarada como parte integrante da construção da masculinidade e que tem em seu interior a possibilidade de demonstração da misoginia, em conjunto com o conceito de representação dos papéis sociais de gênero. Buscamos analisar a representação dos papéis de gênero trazidos no conto por aqueles que são descritos como figuras de convívio do protagonista, ou seja, a mãe e o pai de Artur, assim como o amigo Carlinhos e a colega Glorinha, para fundamentar a análise discursiva e a representação desses papéis sociais com os discursos do protagonista Artur.

\section{ANALISANDO O CONTO}

Nos anos 1950, o Brasil demonstra uma maior interferência exterior, principalmente dos Estados Unidos, incentivando progressivamente o consumismo em combinação com o crescimento da classe média, sendo proporcionado no país mais empregos, em uma ânsia de transfazer a cultura para alcançar a modernização, dando crédito às concepções da juventude.

À princípio - e como deixa sugerido o nome, o conto parece girar em torno de uma questão financeira, apresentando Artur, o protagonista, como uma pessoa sempre preocupada em adquirir dinheiro, ocasionalmente ou não, porque não o tem. Conversa com a mãe, com o pai, com o amigo Carlinhos, mas quer simplesmente tê-lo, e não pensar em uma forma de obtê-lo.

"Se eu tivesse dinheiro..." pensava Artur, e um desejo de entesourar, de possuir com tranquilidade, dava a seu rosto um ar des- 
prendido e contemplativo.

- Não sou um jogador.

- Deixe de tolices, respondeu a mãe. Não recomece com histórias de dinheiro.

$\mathrm{Na}$ realidade ele não tinha vontade de iniciar nenhuma conversa premente que terminasse em soluções. Um pouco da mortificação do jantar da véspera sobre mesadas, com o pai misturando autoridade e compreensão e a mãe misturando compreensão e princípios básicos - um pouco da mortificação da véspera pedia, no entanto, prosseguimento, (LISPECTOR, 2016, p. 227).

Analisando discursivamente, é possível entender que a reação do protagonista tem referência direta com a dominação masculina, esta construção simbólica que alicerça ao papel social masculino a incorporação do domínio, um poder - aqui visto como poder de decisão, inclusive financeiro -, uma familiarização daquilo que aparentemente observava e reproduzia em casa, no que tange aos papéis sociais de gênero, partindo então das interações dessa estrutura de seu convívio.

É, sem dúvida, à família que cabe o papel principal na reprodução da dominação e da visão masculinas; é na família que se impõe a experiência precoce da divisão sexual do trabalho e da representação legítima dessa divisão, garantida pelo direito e inscrita na linguagem (BOURDIEU, apud. Dicionário Crítico de Gênero, p. 80).

Sua posição enquanto de sexo masculino deveria garantir-lhe, eventualmente, a dominação observada, estereotipada e desejada, que the garantiria o poder sobre o pensar e sobre o decidir.

Clarice, em um cotidiano restrito de tempo, descreve os anseios e pensamentos de Artur, corroborando as oposições binárias demonstradas através do personagem. Oposições estas em que o respeito à autoridade, ou simplesmente o respeito é demonstrado apenas às figuras masculinas trazidas no conto, e o desprezo, o descaso, e até mesmo o desrespeito é obtido relacionado às figuras femininas. Essa modelagem do "ser homem" (tão idealizada por Artur) e "ser mulher" é construída socialmente, assim como o desejo de perpetuação dessas relações de gênero, atribuindo papéis específicos que acabam por desvalorizar, por excluir de oportunidades, de espaços, de voz as mulheres, introduzindo-as à espaços e lugares considerados inferiores, assim como seus afazeres e opiniões - considerados baixos, mesquinhos.

\section{O CONVÍVIO MASCULINO}

Três são os personagens que permeiam o conto envolto na figura de Artur. Seu pai ${ }^{6}$, cujo nome não é mencionado e cuja participação é secundária durante os diálogos com a mãe, mas sempre demonstrando autoridade e contrastando com a subjugada representação materna.

- Eu também tenho as minhas preocupações mas ninguém liga. Quando digo que preciso de dinheiro parece que estou pedindo para jogar ou para beber!

- Desde quando é que o senhor admite que podia ser para jogar ou para beber? disse o pai entrando na sala e encaminhando-se para a cabeceira da mesa. Ora essa! que pretensão!

Ele não contara com a chegada do pai. Desnorteado, porém habituado, começou:

- Mas papai! Sua voz desafinou numa revolta que não chegava a ser indignada. Como contrapeso, a mãe já estava dominada, (...) - Vá saindo que está na sua hora, cortou o pai. Artur virou-se para a sua mãe. Mas esta passava manteiga no pão, absorta e prazerosa. Fugira de novo. A tudo diria sim, sem dar nenhuma importância. (LISPECTOR, 2016, p. 229).

A palavra "mamãe" não aparece no conto, como observada com a palavra papai, que sugere um palavreado menos desafiador e mais infantilizado. Entretanto, para Del Priore (2013), a palavra significa "a perda de prestígio do patriarca", enquanto as casas-grandes tiveram uma transição para a vida nas cidades. Antes o termo "senhor pai" era utilizado, demonstrando ainda maior respeito pela imagem dos pais e tutores, mas a modernidade adotada por Getúlio Vargas no Estado Novo, herança do lema positivista "Ordem e Progresso", assim como dos médicos higienistas, e inspirada nos modelos europeus ou norte-americanos,

O novo papel do pai seria o de integrar um sistema capilar onde tudo fosse metódico e

${ }^{6}$ Para Foucault (2015), o pai é a representação da soberania no ambiente familiar, o responsável por instituir o bem nesse ambiente, ou seja, a obediência. Os pais devem saber governar suas famílias, para que então estes membros tenham os comportamentos esperados pela sociedade. 
sistemático. A ciência médica entendia que, para além da função biológica, pais tinham um compromisso com a reprodução social e a construção do "bom cidadão". Deveriam assumir, assim, o projeto de valorizar a intimidade do lar, instaurando a família moderna e higiênica. (...)

À frente desse projeto estava o pai, a quem cabia orquestrar o grupo familiar para que cantasse sem desafinar. Em casa, todos Ihe deviam obediência. (DEL PRIORE, et al. 2013, p. 181).

O pai é a representação de ordem, ao qual se deve obediência; As ordens parecem vir da representação masculina, como sugere a citação, enquanto a feminina está, nas palavras de Clarice, "dominada" e parece se preocupar mais com o pão do que com qualquer outra decisão; o professor da escola em que Artur estuda, como observa-se na citação a seguir.

Sentado na carteira, esperou que o professor se erguesse. $O$ pigarro deste, prefaciando o começo da aula, foi o sinal habitual para os alunos se sentarem mais para trás, abrirem os olhos com atenção e não pensarem em nada. (LISPECTOR, 2016, p. 230).

A autoridade masculina desse ambiente, o colégio ${ }^{7}$, que é aludida brevemente, pertence a essa figura masculina, que disciplina com uma simples demonstração de ordem, aqui demonstrada como "pigarro", em um momento em que a rigidez dos professores eram muito apreciada; e o amigo Carlinhos, do bando ao qual Artur parece fazer parte, e que explicita interesse em mulheres,

- Pelo visto, o cinema está estragado, disse de passagem [Artur] para Carlinhos. Arrependeu-se logo depois de ter falado, pois o colega mal ouvira, ocupado com a menina. Não era necessário diminuir-se aos olhos do

\footnotetext{
${ }^{7} \mathrm{~A}$ educação da década de 1950 é restritiva, ou seja, direciona-se geralmente para os grupos elitistas. Em lugares como o Brasil, onde a população "é mais vulnerável à exploração", a educação fora dessa camada mencionada só ocorria se fosse interferir diretamente no que importava economicamente, ou seja, ao progresso, à modernização. (Dicionário crítico de gênero, 2015)

Alguns autores afirmam que, mesmo nas escolas mistas - ainda raríssimas no período, o que podemos definir na atualidade como currículo era empregado com relação às representações de gênero de forma desigual, assim como "atitudes diferentes entre meninos e meninas" adotados pelos professores. Aos homens, uma educação que os auxiliasse em futuras conquistas, o domínio da "eloquência máscula" para ser utilizada na "dominação social" política ou no mundo dos negócios. (BAUBÉROT, el. al., 2013)
}

outro, para quem uma sessão de cinema só tinha a ganhar com uma garota. (LISPECTOR, 2016, p. 232).

"Era de se esperar" este comportamento, vindo de um rapaz em busca da comprovação de sua virilidade. Como predador, conquistador, era seu papel social de gênero. Sobre isso,

$\mathrm{Na}$ ampla maioria dos agrupamentos humanos a masculinidade foi associada ao poder, quando não à superioridade em relação À feminilidade, vista muitas vezes como rebaixamento e inferioridade (...) Como indicativo de poder a masculinidade deve ser sempre exposta e disputada. (...) à masculinidade associa-se a força, a energia, a coragem, o uso da razão, a competitividade, a rudeza, o desleixo consigo mesmo, a falta de cuidado com o outro, (...) e um zelo pela honra, a atribuição de prover, manter e defender o grupo doméstico, a família. (Dicionário crítico de gênero, 2015, p. 438 e 439. Grifos do autor).

O desejo masculino sobre seu futuro papel social "se manifesta através da ambição exposta em se forjar um homem completo (BABÉROT, et al., p. 197) ", ou seja, um estereótipo que pode idealizar a figura do pai, maduro, mas também do jovem rapaz, aventureiro, com vigor físico.

Enquanto as famílias de classe média vivem a lenta transição entre a infância e a vida adulta, em processo de mudanças que incentiva o consumo, a prática esportiva para afastar os jovens do pensamento sexual, e ao mesmo tempo os lugares dessa prática como locais de encontro desavisado; em que o acesso à informação se populariza, e os jovens têm opções de clubes, cinemas, lazer sem a companhia dos pais, com a oportunidade de passar mais tempo juntos. Neste ínterim, a necessidade de identificação surge, e imagens estereotipadas, providas de valores e atitudes são trazidas das vivências oportunizadas.

A figura do pai, o ser autoritário, honrado, do marido, superior, dominante, ativo, figura a ser obedecida, pois responsável e possuidor da família moderna e higiênica. O local onde este homem mandava era no seu lar, pois no trabalho obedecia ao patrão. (DEL PRIORE et al., 2013, p. 181) Indo além, outra imagem estereotipada surge, em 1950, com o cinema hollywoodiano, a do jovem rebelde, interpretada por James Dean. 
Mesmo assim, não precisaremos aprofundar esse estereótipo, porque não era do cinema que seu modelo ideal vinha, apesar de certamente ter influenciado outros meios de comunicação e de consumo, mas da televisão e da publicidade, que, segundo Müller (2013), cristalizava as diferenças entre os sexos, onde o homem era mostrado "ao volante do carro mais moderno, da motocicleta mais possante, da lancha mais veloz", o carro que populariza-se e possibilita algumas liberdades; ou seja, um homem de negócios, com investimentos, dinheiro e poder sobre sua família. Na primeira citação, já incluída no texto, e a seguinte, ainda não apresentada:

(...) "Se eu tivesse dinheiro..." pensava Artur, e um desejo de entesourar, de possuir com tranquilidade, dava a seu rosto um ar desprendido e contemplativo. (LISPECTOR, 2016, p. 227)

"Quando eu tiver minha mulher e meus filhos tocarei a campainha daqui [da casa de seus pais] e farei visitas e tudo será diferente", pensou. (Idem, p, 229).

Artur toma como futura propriedade a esposa e os filhos ${ }^{8}$. Minha. Meus. O modelo de autoridade, autonomia e apropriação desejado por Artur é um modelo ideal, provavelmente inalcançável, que entretanto, é perseguido e submetido à provas - inclusive pelos próprios homens, para a reafirmação esse modelo, mesmo que mediante omissões e mentiras, como podemos interpretar no conto:

- Você então viu logo que Glorinha estava querendo ser convidada pro cinema? Disse Carlinhos, e ambos olharam com curiosidade a menina que se afastava segurando a pasta. Pensativo, Artur continuou a andar ao lado do amigo, olhando as pedras no chão.

- Se você não tem dinheiro para duas entradas, eu empresto, você paga depois.

Pelo visto, do momento em que tivesse dinheiro seria obrigado a emprega-lo em mil coisas.

- Mas depois eu tenho que devolver a você

${ }^{8}$ Historicamente, a redução da mulher ao papel de mãe e esposa devotada representou esse compromisso entre o pai e o poder médico. O homem, expropriado de terras, bens e escravos, através da higiene, colocou seus gênitas à serviço do Estado. Em contrapartida, foi-lhe dado o direito de concentrar sobre a mulher toda a carga de dominação antes distribuída sobre o grupo familiar e demais dependentes da propriedade. A esposa passou a ser a única propriedade privada. De propriedade jurídico-religiosa, a mulher passou a propriedade higiênico-amorosa do homem (COSTA, 2004, p. 251). e já estou devendo ao irmão de Antônio, respondeu evasivo.

(...)

- Pelo visto, disse desviando do amigo a raiva, pelo visto basta você ter uns cruzeirinhos que mulher logo fareja e cai em cima.

Os dois riram. Depois disso ele ficou mais alegre, mais confiante. Sobretudo menos oprimido pelas circunstâncias.

(...) Durante o almoço ele pensou com rispidez em fazer ou não fazer dívidas e sentia-se um homem aniquilado.

(...)

(...) Mas à porta do cinema não pôde deixar de pedir emprestado a Carlinhos, porque lá estava Glorinha com uma amiga.

(...)

Diante disso, Carlinhos pagou a entrada da amiga e Artur recebeu disfarçado o dinheiro da entrada de Glorinha (LISPECTOR, 2016, p. 230 à 232. Grifos nossos).

Clarice, ao escrever que "Glorinha estava querendo ser convidada pro cinema" sugere uma prática que Claudia Maia (2011) descreve como footing, ou seja, em lugares públicos, os jovens reuniram-se e a comunicação intersexual ocorria por meio de olhares, de leitura corporal, subentendendo-se através disso. Maia acrescenta:

Como parte das estratégias de desenvolvimento do dispositivo amoroso com vistas ao matrimônio foram criados, por um lado, espaços públicos específicos mais distantes do olhar vigilante dos pais para que os enamorados pudessem vivenciar suas emoções românticas e principalmente se apaixonarem. É o caso dos bailes, muitos dos quais organizados para proporcionar o encontro "por acaso" dos pares; as horas dançantes, o escurinho do cinema, o passeio na praça (Idem, p. 145-146).

É possível, de acordo com a sugestão de Clarice, imaginar que os jovens tivessem a oportunidade de encontrar-se, e que o footing também seria passível de verdade.

Carlinhos, em sua fala, impõe para Artur a reafirmação de sua masculinidade, induzindo- o a levar Glorinha ao cinema. Artur realizará a prova mediante a omissão visto que não teria meios financeiros para concretizar a vontade de Glorinha, ao ser financiado pelo amigo.

Esta prova pela qual o protagonista passa pode ser interpretada por Foucault como um 
ritual, que qualifica e deve ser parte integrante daqueles possuidores do discurso, ou seja, esse ritual:

(...) define os gestos, os comportamentos, as circunstâncias, e todo o conjunto de signos que devem acompanhar o discurso; fixa, enfim, a eficácia suposta ou imposta das palavras, seu efeito sobre aqueles aos quais se dirigem, os limites de seu valor de coerção. Os discursos (...) não podem ser dissociados dessa prática de um ritual que determina para os sujeitos que falam, ao mesmo tempo, propriedades singulares e papéis preestabelecidos. (FOUCAULT, 2011, p. 39).

Mesmo que Artur secretamente sinta-se desconfortável com a opressão, a raiva perante a prova imposta não é direcionada ao amigo, o juiz do momento, porque é visto como cumprindo seu papel de companheiro masculino na construção social da masculinidade, que passa por rituais, provas, que precisa permanentemente ser ratificada, comprovando sua representação. Ainda nesse recorte, é possível observar também a validação da virilidade por Carlinhos, quando também tem sua acompanhante na ida ao cinema. Glorinha pode ser colocada como parte secundária na provação, e à ela recai a culpa da omissão que receberá de Artur, como veremos adiante.

\section{O CONVÍVIO FEMININO}

Novamente, três são as personagens relevadas por Artur em seu conto. A primeira com quem tem contato, sua mãe, cujo nome também não é revelado, numa posição de submissão, possivelmente explicada pela experiência pessoal no âmbito familiar, observada quando Artur desrespeita a autoridade da mãe, à mesa, e o pai responde "- Olha o modo como você fala com a sua mãe, diz o pai sem severidade" (LISPECTOR, 2016. Grifos nossos), em uma espécie de naturalização de comportamento, já que a resposta é simplesmente para apaziguar os ânimos, conduzir bem a criação do filho, mas não realmente ensiná-lo a respeitar a figura materna ou feminina, por isso a descrição de que a correção ocorre, mas sem severidade. Essa relação desigual trazia consigo "maridos ciumentos, grosseiros, controladores, adúlteros e um cotidiano de violência física e simbólica, desvelando a situação de submissão e status de incapazes das mulheres dentro do casamento" (MAIA, 2011, p. 157). A naturalização dessa agressividade tende a culpabilizar a vítima, que aqui apresenta-se como a mulher, gerando a misoginia, que será trabalhada adiante. Às mulheres, de acordo com Maia, era aconselhado a paciência, assim como o senso de responsabilidade pelo comportamento do marido, fazendo-as pensar que provocavam a brutalidade que recebiam.

Em uma construção cultural, de experiências e observações, Artur demonstra misoginia no convívio com as personagens femininas, observado no tratamento de desprezo empregado com a mãe, com Glorinha e com a amiga de Glorinha que a acompanha no cinema. Tal sentimento "nasce no seio da sociedade e de suas representações" (Dicionário Crítico de Gênero, 2015 , p. 461), e às mulheres é direcionado pelo simples fato de serem mulheres e de possuírem papéis sociais oprimidos, em que todas são caracterizadas em um mesmo contexto e destino, provado pelo fato de Artur julgar também a amiga de Glorinha, que foi acompanhada por Carlinhos no cinema, quando pensa se ela foi tão ou menos exploradora que Glorinha.

Além disso, a passagem em que Artur faz menção ao comportamento feminino em relação ao dinheiro pode clarificar esse posicionamento, quando exterioriza sua raiva, anteriormente direcionada ao amigo por induzi-lo a emprestar dinheiro para pagar a entrada do cinema de Glorinha, raiva essa, posteriormente, conduzida às mulheres, em âmbito geral: "- Pelo visto, disse desviando do amigo a raiva, pelo visto basta você ter uns cruzeirinhos ${ }^{9}$ que mulher logo fareja e cai em cima" (LISPECTOR, 2016, p. 231).

Características malignas são atribuídas às mulheres na demonstração de misoginia, e vão desde a avareza, a incapacidade, ou moralidade fraca (Dicionário crítico de Gênero).

Mais tarde, porém, indagou-se se tinha ou não sido explorado. E sua angústia foi tão intensa que ele parou diante da vitrina com uma cara de horror. (...) "Pelo visto, fui...", concluiu e não conseguia sobrepor sua ${ }^{10}$ có-

\footnotetext{
${ }^{9}$ Cruzeiro era a moeda brasileira do período em questão.

${ }^{10} \mathrm{Assim}$, a misoginia nasce de um conjunto de representações que permearam a educação de homens e mulheres em diferentes tempos e culturas. Portanto, só pode ser entendida como constructo cultural que produz experiências e crenças misóginas, em que as mulheres aparecem universalizadas num feminino que é abstrato por desconsiderara [sic] pluralidade dos contextos e das múltiplas lutas das mulheres concretas (Dicionário Crítico de Gênero, 2015, p. 463).
} 
lera ao perfil sem culpa de Glorinha. Aos poucos a própria inocência da menina tornou-se a sua culpa maior: "Então ela explorava, explorava, e depois ficava toda satisfeita vendo o filme? " Seus olhos se encheram de lágrimas. "Ingrata", pensou ele escolhendo mal uma palavra de acusação. (...) Parecia-lhe agora, de fora para dentro e sem nenhuma vontade, que ela deveria ter pago daquele modo a entrada do cinema (LISPECTOR, 2016, p. 232 e 233. Grifos nossos).

Exploradora, ingrata, moralmente reprovada, avarenta, incapaz são algumas das características que podemos exportar da fala do protagonista em relação à Glorinha. Exploradora e avarenta por fazê-lo pagar algo que não é para ele, e sim para deleite dela e, sendo assim, que ela mesma deveria pagar. Moralmente reprovada por aproveitar essa exploração, curtindo os benefícios que a ela se direcionaram. Ingrata? A palavra mal escolhida, mas que traz consigo a ideia de alguém desagradável, que busca benefícios advindos de outras pessoas.

Em relação à sua mãe, apesar da aparente sutileza, Artur desqualifica-a, dizendo que:

- Artur, disse a mãe irritadíssima, já me bastam as minhas preocupações!

- Que preocupações? perguntou ele com interesse.

A mão olhou-o seca como a um estranho. No entanto ele era muito mais parente que seu pai, que, por assim dizer, entrara na família. Apertou os lábios.

- Todo mundo tem preocupações, meu filho, corrigiu-se ela entrando então em uma nova modalidade de relações, entre maternal e educadora (LISPECTOR, 2016, p. 228. Grifos nossos).

Endereçando à mãe um olhar, um julgamento de desqualificação, de inutilidade, de desprezo, reprovação por se impor, por se sentir mais do que realmente ele considera que ela seja, um ser privado de preocupações por não ser responsável pelo sustento da família, que "nada faz", ou que realiza atividades subalternas e frívolas, porque domésticas, para as quais não precisa dispor muito esforço ou intelecto. Que preocupações teria, se fica o dia todo em casa? Que responsabilidades teria? Ela não vai se impor, porque se recolherá ao lugar em que foi colocada, de subalternidade, de papel social feminino, de docilidade, demonstrando o medo de ser isolada, assim como a necessidade de manter-se "na linha". Ela precisa da aceitação do filho, outra figura masculina em sua vida, que a mantém - ou a lembra de manter-se - em posição inferior. Isso pode ser explicado por Robin Lakoff, que afirma:

Veremos que o efeito geral da "linguagem das mulheres" - que significa tanto a linguagem restrita ao uso das mulheres quanto a linguagem descritiva das mulheres simplesmente - é esse: ela submerge a identidade pessoal da mulher, por negar a ela os meios de expressar-se fortemente, por um lado, e por encorajar expressões que sugerem trivialidade do assunto e incerteza sobre ele; e, quando se está falando sobre uma mulher, por trata-la como objeto - sexual ou outro -, mas nunca como uma pessoa com posições individuais. (...)

O efeito maior dessas discrepâncias é que às mulheres é sistematicamente negado acesso ao poder, com o pretexto de que elas não são capazes de sustenta-lo, (...) e a ironia é que as mulheres são produzidas para sentir que merecem tal tratamento, por causa das inadequações em sua própria Inteligência e/ou educação (LAKOFF, et al., 2010, p. 17 e 18).

$E$, acrescenta que a insignificância do olhar masculino em relação ao feminino se dá quando apenas assuntos considerados masculinos são vistos como importantes ou significativos, restando às mulheres que tomem decisões consideradas frívolas, externas ao que interessa aos homens, ou seja, à elas "são relegadas decisões insignificantes como distração". (Idem)

As expectativas sociais em relação aos homens e mulheres é diferente, e, na descrição feita por Clarice, a mãe de Artur se curva ao comportamento que Ihe foi ensinado a ter, mesmo que, como consequência, ela não seja levada em consideração ou à sério.

\section{CONSIDERAÇÕES FINAIS}

O conto perpassa pelo ambiente familiar, escolar e público, o que nos permitiu entrar em contato com essas três realidades e seus papéis sociais e sua hierarquia, desde os pais, demonstrando a autoridade paterna e a submissão materna, como o professor, a distância em relação ao footing feminino, assim como o ambiente público, com o amigo do protagonista que Ihe impulsiona a provar sua virilidade enquanto 
homem provedor, mesmo que de forma mascarada, e a aparente indignação por parte de Artur pelo comportamento de Glorinha, que o fez pagar sua entrada no cinema, e foi analisada enquanto ingrata e exploradora, devido a isso.

Os estereótipos desejados pelo protagonista para sua atuação no papel masculino perpassam o ambiente familiar, onde a figura paterna é detentora da autoridade e também coloca os demais membros de sua família como sua propriedade, assim como o estereótipo de virilidade da publicidade da época, que traz o homem bem-sucedido, com muitos bens materiais.

Quando Artur demonstra os pensamentos misóginos sobre sentir-se usado ao pagar a entrada de Glorinha ao cinema é que nos confundimos, ao analisar primitivamente que $o$ protagonista não queria, simplesmente, assumir seu papel social de gênero e sua dominação masculina. Pelo contrário. Artur anseia por este papel, esta representação estereotipada, mas seu desprezo pela representação feminina é tão forte que ele aparece desrespeitando e maldizendo esses sujeitos, assim como aparentemente se naturalizou no discurso social do referido período.

Artur parece, então, aderir às representações de discursos como a misoginia e a dominação masculina, demonstrando um conjunto de percepções e pensamentos que nos leva a considerar tais definições, quando se refere às mulheres.

Naturalizado ou não, a misoginia fez parte do discurso social e das representações no conto de Clarice Lispector, que nos mostra a importância da construção da virilidade, assim como a significante atuação da dominação masculina, através da literatura, descrita no cotidiano de um estudante de classe média, que sofre interdições midiáticas, familiares e sociais no geral. Uma possibilidade de análise futura de grande importância seria na área linguística, que possibilitaria adentrar nos pormenores das falas, elucidando outro viés, que não o trazido aqui, entretanto o complementaria para uma possível totalidade.

Há quem diga que a arte imita a vida, há quem acredite no contrário. $\mathrm{O}$ que realmente importa é que a vida está contida nas linhas literárias, e nos possibilita pensar questões silenciadas pela antes caracterizada história oficial. Eis um agradecimento à literatura e seus reflexos sociais.

\section{REFERÊNCIAS}

BAUBÉROT, A. Não se nasce viril, torna-se viril. In. CORBIN, J. C.; VIGARELLO, G. História da Virilidade. Petrópolis: Vozes, 2013. p. 189-238.

BERGER, C. N. Misoginia. In. COLLING, A. M; TEDESCHI, L. A. (org.). Dicionário crítico de gênero. Dourados, ed. UFGD, 2015. p. 461463.

BORDIEU, P. A dominação masculina. 11. ed. Rio de Janeiro. Bertrand Brasil, 160p. 2002.

CAMPOS, R. D. de. Mulheres e crianças na imprensa paulista (1920 - 1940): Educação e história. São Paulo: Ed. UNESP, 2009.

CHARTIER. R. O mundo como representação. Estud. av. v. 5, n. 11. São Paulo jan./abr. 1991.

COSTA, J. F. Ordem médica e norma familiar - Rio de Janeiro: Edições Graal, 2004.

DEL PRIORE, M. História do amor no Brasil. São Paulo: Contexto, 2012.

Pais de ontem: transformações da paternidade no século XIX. In: DEL PRIORE, $M$. et al. História dos homens no Brasil. São Paulo, Ed. Unesp, 2013. P. 153-184.

FOUCAULT, M. A ordem do discurso: aula inaugural no Collége de France, pronunciada em 2 de dezembro de 1970. São Paulo: Loyola, 2011.

Paz e Terra, 2015.

LAKOFF, R. Linguagem e lugar da mulher (1973). In: LAKOFF, R. et al. Linguagem.

Gênero. Sexualidade: clássicos traduzidos. São Paulo: Parábola Editorial, 2010. p. 13-30.

LISPECTOR, C. In: MOSER, B. (Org.) Todos os contos. 1. ed. Rio de Janeiro: Rocco, 2016.

MAIA, C. A invenção da solteirona:

Conjugalidade moderna e terror moral: Minas Gerais 1890-1948. Ilha de Santa Catarina: Ed. Mulheres, 2011.

MOSER, B. Clarice, uma biografia. São Paulo: Cosac Naify, 2011. 
MÜLLER, A. Não se nasce viril, torna-se: juventude e virilidade nos "anos 1968". In: DEL PRIORE, M.; AMANTINO, M. História dos homens no Brasil. São Paulo, Ed. Unesp, 2013. P. 299-334.

PINSKY, C. B. Mulheres dos Anos Dourados. São Paulo: Contexto, 2014.

RAGO, M. Os prazeres da noite: prostituição e códigos da sexualidade feminina em São Paulo, 1890 - 1930. Rio de Janeiro: Paz e Terra, 1991.

SANT'ANNA, D. B. de. Masculinidade e virilidade entre a Belle Époque e a República. In: DEL PRIORE, M.; AMANTINO, M. História dos homens no Brasil. São Paulo, Ed. Unesp, 2013. p. $245-266$.

STEARNS, P. N. História da Sexualidade. São Paulo: Contexto, 2010.

\section{LA CONSTRUCCIÓN DE LA MASCULINIDAD Y LA MISOGINIA EN EL CONTO COMENZOS DE UNA FORTUNA, DE CLARICE LISPECTOR (1960)}

Resumen: Brasil, siglo XX. Clarice Lispector, literata y periodista, elaboró cuentos, columnas de periódicos y libros. El cuento de la autora aquí analizado, titulado Comienzos de una fortuna, es pasible de análisis por demostrar a las relaciones de género, pasando por las relaciones de poder y de jerarquía de los papeles sociales binarios. Con el intento de aclarar sobre la construcción de la masculinidad, para entonces constatar la misoginia a través de la representación del personaje principal Artur, empleamos el análisis del discurso francés con Michel Foucault, anhelando explicar las interdicciones del discurso de género, de familia nuclear, con el fin de y que, a partir del discurso adoptado por Clarice Lispector en el discurso del protagonista y de las representaciones que lo rodean, y si, a partir del discurso adoptado por Clarice Lispector en el discurso del protagonista y de las representaciones que lo rodean, sus líneas, la mirada del personaje principal conducido a las mujeres con las que el mismo se interrelaciona tiene la posibilidad de ser identificado como misógino. En el análisis, nos parece que Artur anhela por la dominación masculina, adoptando como representación estereotipada la figura paterna de autoridad y propietario de los demás integran- tes de la familia, así como la representación de un hombre exitoso le es deseada. Su desprecio por la representación femenina es tan aguda que maldice a estos sujetos femeninos, demostrando Artur se encara de las representaciones de discursos como la misoginia y la dominación masculina, en un conjunto de percepciones y pensamientos que nos llevan a considerar tales definiciones. Por último, la literatura se presenta como fuente de análisis histórico de lo que se silenciaba por parte de la anterior historia oficial. Palabras Clave: Clarice Lispector; Masculinidad; Misoginia; Representación. 